\title{
The Impact of ABO Blood Group on Biochemical Recurrence after Radical Prostatectomy
}

\author{
Shahait $M^{1}$, Fares $S^{2}$, Mukherji $D^{3}$, Hout $M^{1}$, Bachir $B G^{1}$, Khauli $R^{1}$ and Bulbul $M A^{1^{*}}$ \\ ${ }^{1}$ Surgery Department/Urology Division, American University of Beirut Medical Center, Beirut, Lebanon \\ ${ }^{2}$ Rafic Hariri School of Nursing, American University of Beirut, Beirut, Lebanon \\ ${ }^{3}$ Division of Hematology-Oncology, Department of Internal Medicine, American University of Beirut Medical Center, \\ Beirut, Lebanon
}

*Corresponding author: Muhammad Bulbul, Surgery Department/Urology Division, American University of Beirut Medical Center, Beirut, Lebanon, E-mail: mb30@aub.edu.Ib

\begin{abstract}
Introduction: The $\mathrm{ABO}$ antigens are expressed on the surface of red blood cells, epithelial cells, and endothelial cells. The association between different $A B O$ blood group and several conditions such as VTE, CAD, and several neoplasms is well documented in the literature. The aim of this study is to examine the impact of $A B O$ blood group on the biochemical failure after radical prostatectomy.

Methods: After Institutional research board approval; we retrospectively reviewed the radical prostatectomy database (1998-2012) to examine the association between the $\mathrm{ABO}$ blood group and biochemical recurrence. Hazard ratio (HRs) and their 95\% confidence intervals were calculated using Univariable and multivariable Cox regression models.

Results: 385 patients underwent open radical retropubic prostatectomy between 1998 and 2012. Follow-up more than 2 months was available for 229 patients. Seventy-Five patients developed biochemical failure, defined as PSA > $0.2 \mathrm{ng} / \mathrm{dl}$. The 10-year Biochemical recurrence-free survival were $53.6 \%(95 \% \mathrm{Cl}, 39.8 \%-65.7 \%)$ for blood group $\mathrm{O}$, $58.0 \%$ for blood group $\mathrm{A}(95 \% \mathrm{Cl}, 43.1 \%-70.3 \%)$ and $61.8 \%$ (95\% Cl, 33.1\%-81.1\%) for blood group B. The log-rank test showed no significant associations between blood group and PSA failure at the univariate level and Multivariate. On the other hand, pre-op PSA, Gleason score, surgical margin and extra-prostatic extension were significantly associated with biochemical recurrence-free survival.
\end{abstract}

\section{Keywords}

Radical prostatectomy, Biochemical recurrence, ABO blood group, Prostate cancer

\section{Introduction}

One-third of patients who undergo radical prostatectomy will develop biochemical recurrence as a herald sign of disease recurrence [1]. Intriguingly, the outcome of those patients varies; some will have a local recurrence while other will progress to metastatic disease. There are multiple clinical and pathological features that predict the biochemical recurrence such as Gleason Score, Lymphovascular invasion, Seminal vesicle involvement and positive surgical margins [2]. Recently, there has been heightened interest in exploring the molecular basis of this heterogeneity in the outcome of patients with biochemical recurrence. Ross, et al. found that genomic classifier "decipher" has better ability to predict progression after biochemical recurrence than nomograms based on clinic-pathological features alone [3]. Moreover, other factors such as the use of metformin, statins, and smoking may alter the risk of biochemical recurrence.

The $A B O$ antigens are expressed on the surface of red blood cells, epithelial cells, and endothelial cells [4]. Their immunological function is well-studied, and they appear to play a role in the pathogenesis of diseases. The association between different $A B O$ blood groups and multiple conditions such as venous thromboembolisms (VTE), coronary artery disease (CAD), and several neoplasms has been well documented [5,6]. As in pancreatic cancer patients with blood type $A$ as compared

Citation: Shahait M, Fares S, Mukherji D, Hout M, Bachir BG, et al. (2018) The Impact of ABO Blood Group on Biochemical Recurrence after Radical Prostatectomy. Int Arch Urol Complic 4:040. doi.org/10.23937/2469$5742 / 1510040$

Accepted: July 09, 2018: Published: July 11, 2018

Copyright: (c) 2018 Shahait M, et al. This is an open-access article distributed under the terms of the Creative Commons Attribution License, which permits unrestricted use, distribution, and reproduction in any medium, provided the original author and source are credited. 
to blood type $O$ had a greater risk of developing pancreatic cancer, however, patients with blood type $B$ or $A B$ did not [6].

The association between blood group and prostate cancer isn't well studied.

Due to the long nature of the disease, we opted to study the impact of $A B O$ blood group on soft clinical sign namely biochemical recurrence after radical prostatectomy.

\section{Methods}

After Institutional review board approval, we retrospectively reviewed the radical prostatectomy database at the American University of Beirut between (1998-2012) and studied the association between the ABO blood group of 385 patients and subsequent biochemical recurrence. Follow-up more than 2 months was available for 229 patients. Seventy-Five patients developed biochemical failure, defined as PSA $>0.2 \mathrm{ng} /$ $\mathrm{dl}$ in two consecutive measurements. $A B O$ status, preop PSA, Gleason score, pathological stage, the status of surgical margins of the RP specimen were recorded and reviewed. Tumors were staged according to the 2009 TNM classification.

\section{Statistical analysis}

All statistical analyses were conducted using SPSS version 23.0 and STATA version 13.1 for Windows. All tests were two-sided and a $p$-value $<0.05$ was considered significant. The following variables were considered for statistical analysis: age at RP, preoperative PSA level, ABO blood group, Gleason score, extraprostatic extension, seminal vesicle involvement, positive surgical margin and adjuvant therapy which was included as a time-dependent covariate. Continuous variables were summarized using means and standard deviations (SD) and categorical factors using frequencies and per- centages. Variables were compared across blood group categories using the chi-square test, Fisher's exact test, independent samples t-test and one-way ANOVA as appropriate. Kaplan-Meier curves were plotted and compared across the categories of the main independent variable, blood group, using the log-rank test. Univariable and multivariable cox regression models were carried out to determine independent predictors of PSA failure. Variables that was significant at $p<0.2 \mathrm{ng} /$ $\mathrm{dl}$ at the univariable level was entered into the multivariable model. Age of patients and blood group were forced into the multivariable model. Hazard ratios (HR) and their $95 \%$ confidence intervals $(\mathrm{Cl})$ were reported. The proportional hazards assumption was tested with Schoenfeld residuals. The ability of the cox model to discriminate between PSA failures and non-failures was measured by the Harrell's c statistic.

\section{Results}

Data from 229 patients with prostate cancer were retrieved for this study. There were only 14 patients with the blood group $A B$ and were therefore removed from the analysis for model convergence. The final study sample included 215 patients with mean age 62 years $(S D=6.10)$. Ninety patients $(41.9 \%)$ had blood group O, 85 patients (39.5\%) had blood group A and 40 patients (18.6\%) had blood group B. Seventy-one patients $(33.0 \%)$ had a Gleason score $<=6,112(52.1 \%)$ had a Gleason score equal to 7 and 32 patients (14.9\%) had a Gleason score $>=8$. Sixty patients $(27.9 \%)$ had an extraprostatic extension, 108 patients $(50.2 \%)$ had a positive surgical margin and 26 patients only (12.1\%) had a seminal vesicle involvement. As for the pathological stage, 48 patients (22.3\%) had T2a and T2b disease, 103 (47.9\%) had T2c and 64 (29.8\%) had T3. The mean pre-surgery PSA score was $8.89(\mathrm{SD}=6.65)$. Characteristics of the total sample are presented in Table 1 . We

Table 1: Clinical characteristics of the total sample and across $A B O$ blood group.

\begin{tabular}{|c|c|c|c|c|c|c|}
\hline \multirow{2}{*}{\multicolumn{2}{|c|}{ Variable }} & Total & Blood group 0 & Blood group A & Blood group B & P-value \\
\hline & & $N(\%)$ & $N(\%)$ & $N(\%)$ & $N(\%)$ & \\
\hline \multicolumn{2}{|l|}{$n$} & 215 & $90(41.9 \%)$ & $85(39.5 \%)$ & $40(18.6 \%)$ & \\
\hline \multicolumn{2}{|c|}{ Age in years (Mean $\pm S D$ ) } & $61.87 \pm 6.14$ & $62.14 \pm 5.54$ & $61.76 \pm 6.56$ & $62.07 \pm 6.35$ & 0.818 \\
\hline \multirow[t]{3}{*}{ Gleason Score (GS) } & $<=6$ & $71(33.0 \%)$ & $33(36.7 \%)$ & $21(24.7 \%)$ & $17(42.5 \%)$ & \\
\hline & 7 & $112(52.1 \%)$ & $40(44.4 \%)$ & $54(63.5 \%)$ & $18(45.0 \%)$ & \\
\hline & $>=8$ & $32(14.9 \%)$ & $17(18.9 \%)$ & $10(11.8 \%)$ & $5(12.5 \%)$ & 0.080 \\
\hline \multirow{2}{*}{$\begin{array}{l}\text { Extraprostatic } \\
\text { Extension (EPE) }\end{array}$} & No & $155(72.1 \%)$ & $68(75.6 \%)$ & $56(65.9 \%)$ & $31(77.5 \%)$ & \\
\hline & Yes & $60(27.9 \%)$ & $22(24.4 \%)$ & $29(34.1 \%)$ & $9(22.5 \%)$ & 0.253 \\
\hline \multirow[t]{2}{*}{ Surgical Margin (SM) } & No & $107(49.8 \%)$ & $45(50.0 \%)$ & $41(48.2 \%)$ & $21(52.5 \%)$ & \\
\hline & Yes & $108(50.2 \%)$ & $45(50.0 \%)$ & $44(51.7 \%)$ & $19(47.5 \%)$ & 0.904 \\
\hline \multirow{2}{*}{$\begin{array}{l}\text { Seminal Vesicle } \\
\text { Involvement (SVI) }\end{array}$} & No & $189(87.9 \%)$ & $80(88.9 \%)$ & $72(84.7 \%)$ & $37(92.5 \%)$ & \\
\hline & Yes & $26(12.1 \%)$ & $10(11.1 \%)$ & $13(15.3 \%)$ & $3(7.5 \%)$ & 0.429 \\
\hline \multirow{3}{*}{$\begin{array}{l}\text { Pathological stage } \\
\text { (PT) }\end{array}$} & $\mathrm{T} 2 \mathrm{a}, \mathrm{T} 2 \mathrm{~b}$ & $48(22.3 \%)$ & $19(21.1 \%)$ & $18(21.2 \%)$ & $11(27.5 \%)$ & \\
\hline & T2c & $103(47.9 \%)$ & $46(51.1 \%) d$ & $37(43.5 \%)$ & $20(50.0 \%)$ & \\
\hline & T3 & $64(29.8 \%)$ & $25(27.8 \%)$ & $30(35.3 \%)$ & $9(22.5 \%)$ & 0.589 \\
\hline \multirow[t]{2}{*}{ Adjuvant therapy } & No & $160(77.3 \%)$ & $70(78.7 \%)$ & $64(78.0 \%)$ & $26(72.2 \%)$ & \\
\hline & Yes & $47(22.7 \%)$ & $19(21.3 \%)$ & $18(22.0 \%)$ & $10(27.8 \%)$ & 0.723 \\
\hline \multicolumn{2}{|c|}{ Pre-op PSA (Mean \pm SD) } & $8.89 \pm 6.65$ & $8.50 \pm 5.62$ & $9.94 \pm 7.76$ & $7.50 \pm 5.90$ & 0.128 \\
\hline
\end{tabular}




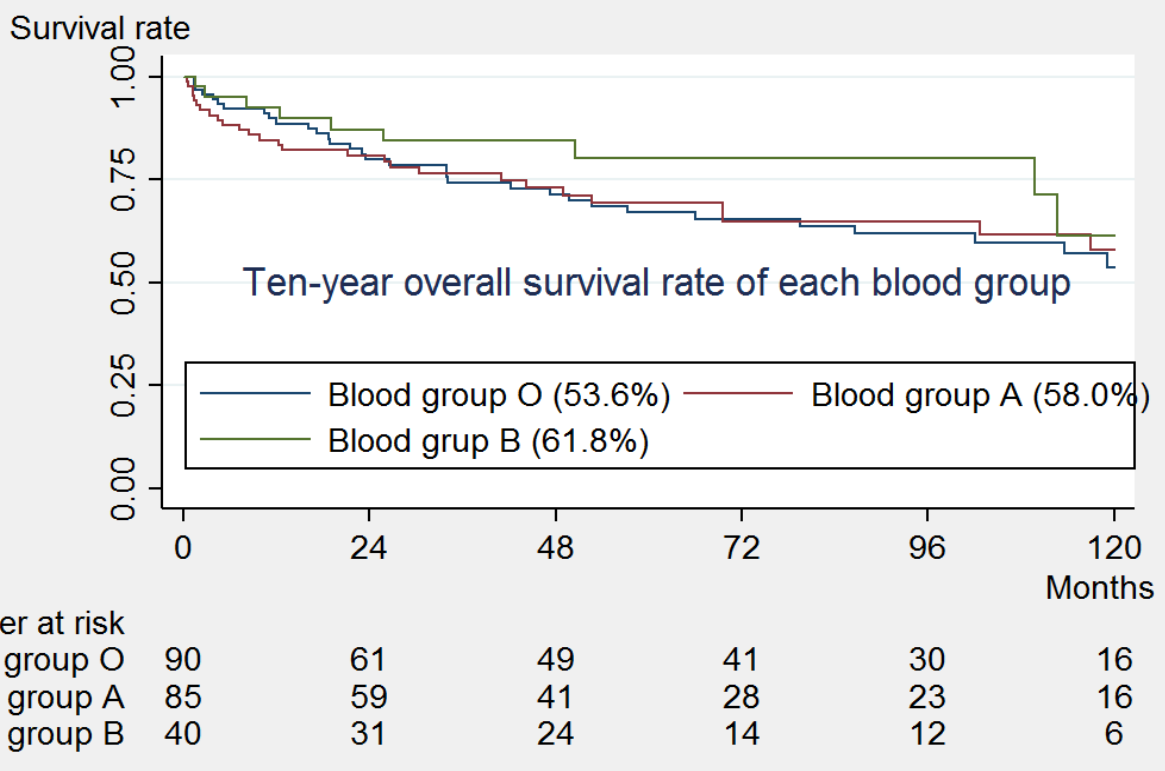

Figure 1: Overall survival curves by blood group.

Table 2: Unadjusted associations between patient characteristics and PSA failure.

\begin{tabular}{|c|c|c|c|}
\hline Variable & Hazards ratio & $95 \% \mathrm{Cl}$ & $p$ \\
\hline Age & 1.00 & $(0.96,1.04)$ & 0.958 \\
\hline \multicolumn{4}{|l|}{ Blood group } \\
\hline $\mathrm{O}$ & Reference & & \\
\hline$A$ & 0.96 & $(0.58,1.61)$ & 0.894 \\
\hline B & 0.63 & $(0.30,1.33)$ & 0.225 \\
\hline \multicolumn{4}{|c|}{ Gleason score } \\
\hline$<=6$ & Reference & & \\
\hline 7 & 2.00 & $(1.09,3.60)$ & 0.025 \\
\hline$>=8$ & 2.40 & $(1.16,4.97)$ & 0.019 \\
\hline Pre-op PSA & 1.03 & $(1.00,1.07)$ & 0.045 \\
\hline \multicolumn{4}{|c|}{ Pathological State } \\
\hline 1 & Reference & & \\
\hline 2 & 1.18 & $(0.61,2.31)$ & 0.620 \\
\hline 3 & 1.90 & $(0.96,3.81)$ & 0.066 \\
\hline \multicolumn{4}{|c|}{ Seminal vesicle involvement } \\
\hline No & Reference & & \\
\hline Yes & 0.62 & $(0.25,1.55)$ & 0.307 \\
\hline \multicolumn{4}{|c|}{ Surgical margin or Extraprostatic extension } \\
\hline None & Reference & & \\
\hline Either & 2.55 & $(1.51,4.31)$ & $<0.001$ \\
\hline
\end{tabular}

also compared the distributions of the clinical characteristics across the blood groups and found no significant associations (Table 1).

\section{Factors associated with PSA failure}

Of the 215 patients, PSA failure was observed in 75 (34.9\%) patients. Median follow-up time was 51 months (Interquartile range $=19-104)$. 10-year survival curves of each blood group are shown in Figure 1. The 10-year survival rates were $53.6 \%(95 \% \mathrm{Cl}, 39.8 \%-65.7 \%)$ for blood group $0,58.0 \%$ for blood group $\mathrm{A}(95 \% \mathrm{Cl}, 43.1 \%$ $70.3 \%)$ and $61.8 \%(95 \% \mathrm{Cl}, 33.1 \%-81.1 \%)$ for blood group $B$. The log-rank test showed no significant associations between blood group and PSA failure at the univariate level (Table 2). Cox regression was carried out
Table 3: Multivariate Cox proportional hazard models of PSA failure.

\begin{tabular}{|c|c|c|c|}
\hline & $\begin{array}{l}\text { Hazard } \\
\text { ratio }\end{array}$ & $95 \% \mathrm{Cl}$ & $p$ \\
\hline Age & 1.00 & $(0.94,1.02)$ & 0.323 \\
\hline \multicolumn{4}{|l|}{ Blood group } \\
\hline $\mathrm{O}$ & Reference & & \\
\hline A & 0.59 & $(0.33,1.05)$ & 0.072 \\
\hline B & 1.25 & $(0.66,2.35)$ & 0.495 \\
\hline$A B$ & 1.22 & $(0.46,3.20)$ & 0.692 \\
\hline \multicolumn{4}{|l|}{ Gleason score } \\
\hline$<=6$ & Reference & & \\
\hline 7 & 1.49 & $(0.80,2.76)$ & 0.209 \\
\hline$>=8$ & 2.213 & $(1.00,4.88)$ & 0.049 \\
\hline Pre-op PSA & 1.03 & $(1.00,1.06)$ & 0.099 \\
\hline \multicolumn{4}{|l|}{ Pathological stage } \\
\hline T1 & Reference & & \\
\hline $\mathrm{T} 2$ & 1.18 & $(0.60,2.32)$ & 0.629 \\
\hline T3 & 1.01 & $(0.45,2.27)$ & 0.980 \\
\hline $\begin{array}{l}\text { Surgical margin or } \\
\text { Extraprostatic extension } \\
\text { None } \\
\text { Either }\end{array}$ & $\begin{array}{l}\text { Reference } \\
2.29\end{array}$ & $(1.22,4.32)$ & 0.010 \\
\hline
\end{tabular}

Cox proportional hazard model of PSA failure. $\mathrm{c}$-statistic $=$ 0.67 .

to determine the variables associated with PSA failure. At the univariate level, patients with a Gleason score 7 ( $\mathrm{HR}=2.00,95 \% \mathrm{Cl}: 1.09-3.60)$ and patients with Gleason score greater than or equal to $8(\mathrm{HR}=2.40,95 \% \mathrm{Cl}$ : 1.16-4.97) were more likely to have failure compared to patients with a Gleason score less than or equal to 6. Patients with higher pre-surgery PSA were also more likely to have a failure ( $\mathrm{HR}=1.03,95 \% \mathrm{Cl}: 1.00-1.07)$ as shown in Table 2. Due to the high association between extraprostatic extension and surgical margin, we created a new variable that takes the value of 1 if either extraprostatic extension or surgical margin is present and 0 if none. The combined variable was included in the regression. Patients with either extraprostatic exten- 
sion or surgical margin were also more likely to have a failure ( $\mathrm{HR}=2.55,95 \% \mathrm{Cl}: 1.51-4.31)$. Although blood group was not associated with failure at the univariate level, we included it in the multivariable cox regression model. In the multivariable model and after adjusting for the clinical characteristics of the patients, blood group remained not associated with PSA failure, while having either an extraprostatic extension or a surgical margin was associated with failure $(\mathrm{HR}=2.57,95 \% \mathrm{Cl}$ : 1.37-4.82, Harrell's c-statistic $=0.64$ ) Table 3.

\section{Discussion}

We studied $A B O$ blood type as a prognostic biomarker in a patient with localized prostate cancer who underwent radical prostatectomy. Blood type was not associated with 10 years BCR free survival rate on univariate and multivariate regression model.

Interestingly, ABO gene is located on the long arm of chromosome 9 which also contains the coding genes for PCA3/DD3 and ABL oncogene $[7,8]$. In an elegant dissection of the genetic pathways involved in prostate carcinogenesis Ribeiro, et al. found that gain at chromosome 9q34 was found in cases with high Gleason score and associated with locally advanced disease and metastasis. However, the regression analysis failed to prove that gain at chromosome 9 is significant independent variable for local invasiveness and metastasis potential [9].

Recently, Ohno, et al. reported on the correlation between $A B O$ blood group and BCR after RP; in contradiction to our finding, he found that $O$ blood group was associated with longer BCR free survival in patients with negative surgical margin [10].

Increasing evidence indicates that Globo $\mathrm{H}$ and Lewis $Y$ are highly overexpressed in various types of malignant tumors including breast, liver, prostate, and pancreatic cancer [11]. The $\mathrm{H}$ antigen is a precursor for the $A B O$ blood group antigens located in intestinal mucosa and body fluids. Individuals homozygous for fut2 nonfunctional alleles would be considered non-secretors as they would not present their blood group antigens on their epithelial cells or secretions. $20 \%$ of people studied in various populations are considered non-secretors [12]. The penetration of fut 2 gene in different populations varies and this may explain the inconsistency between our result and the previously reported results from other populations.

An association between Le(y) and SLe(x) antigens which are blood group related antigens was found to be upregulated in prostate cancer. Le(y) can be found in ducts and basal layer of the glandular epithelium in benign tissue however in carcinoma its expression is greatly increased. The SLe(x) antigen can be found only in ducts but not in the glandular epithelium of benign tissue while in carcinoma $\operatorname{SLe}(x)$ can rarely be found and in some cells found in focal to patchy distribution
[13]. Moreover, a study by Kvist, et al. in 1992 found no association between prostate cancer and blood group antigens [14].

The inconsistency between the results of our study and the above studies can be attributed to several factors; for example, in Ohno, et al. study, there was a subgroup of patients with lymph nodes involvement, whereas all patients had localized disease in this study. Also, we can't not to ruminate the variation in geographic and ethnic distribution the $\mathrm{ABO}$ blood group allele.

It has been postulated that the $\mathrm{ABO}$ blood group antigen may affect the carcinogenesis by altering the levels of tumor necrosis factor-a [15]. Thus, it hampers cell adhesion and immune surveillance. Moreover, it has been documented that the loss of expression of blood group $\mathrm{ABH}$ is associated with worse prognosis of the bladder, colon, and head and neck cancers [16-18]. Indeed, these findings are engrossing in the light of our finding that there is no association between $A B O$ blood group and $B C R$; which is a herald sign of distant metastasis.

There are multiple limitations to our study, first the retrospective nature of the study in addition to small sample size. There is an inherent loss of follow-up in our cohort attributed to the nature of referral from other countries. Moreover, we were unable to investigate our patients for their status as secretors/non-secretors and account for that variation in our study.

We can't preclude the role of $A B O$ blood group on the disease biology and aggressiveness. The ABO blood group might be used to stratify the patients in future studies of personalized adjuvant treatment after surgery. Further studies are needed to elucidate this correlation.

\section{Conclusion}

ABO blood type as a prognostic biomarker was not associated with 10 years BCR free survival rate on univariate and multivariate regression model in patients who underwent radical prostatectomy for localized prostate cancer.

\section{References}

1. Roehl KA, Han M, Ramos CG, Antenor JA, Catalona WJ (2004) Cancer progression and survival rates following anatomical radical retropubic prostatectomy in 3,478 consecutive patients: Long-term results. J Urol 172: 910-914.

2. Antonarakis ES, Feng Z, Trock BJ, Humphreys EB, Carducci MA, et al. (2012) The natural history of metastatic progression in men with prostate-specific antigen recurrence after radical prostatectomy: Long-term follow-up. BJU Int 109: 32-39.

3. Ross AE, Feng FY, Ghadessi M, Erho N, Crisan A, et al. (2014) A genomic classifier predicting metastatic disease progression in men with biochemical recurrence after prostatectomy. Prostate Cancer Prostatic Dis 17: 64-69.

4. Pourazar A (2007) Red cell antigens: Structure and function. Asian J Transfus Sci 1: 24-32. 
5. Zhang H, Mooney CJ, Reilly MP (2012) ABO blood groups and cardiovascular diseases. Int J Vasc Med 2012: 641917.

6. Wolpin BM, Chan AT, Hartge P, Chanock SJ, Kraft P, et al. (2009) ABO blood group and the risk of pancreatic cancer. J Natl Cancer Inst 101: 424-431.

7. Ferguson-Smith MA, Aitken DA, Turleau C, de Grouchy $J$ (1976) Localisation of the human ABO: Np-1: AK-1 linkage group by regional assignment of AK-1 to $9 q 34$. Hum Genet 34: 35-43.

8. Wolter H, Gottfried HW, Mattfeldt T (2002) Genetic changes in stage pT2N0 prostate cancer studied by comparative genomic hybridization. BJU Int 89: 310-316.

9. Ribeiro FR, Diep CB, Jerónimo C, Henrique R, Lopes C, et al. (2006) Statistical dissection of genetic pathways involved in prostate carcinogenesis. Genes Chromosomes Cancer 45: 154-163.

10. Ohno Y, Ohori M, Nakashima J, Okubo H, Satake N, et al (2015) Associations between ABO blood groups and biochemical recurrence after radical prostatectomy. Int J Clin Exp Med 8: 2642-2648.

11. Marionneau S, Cailleau-Thomas A, Rocher J, Le Moullac-Vaidye B, Ruvoën N, et al. (2001) ABH and Lewis histo-blood group antigens, a model for the meaning of oligosaccharide diversity in the face of a changing world. Biochimie 83: 565-573.
12. Koda Y, Tachida H, Pang H, Liu Y, Soejima M, et al. (2001). Contrasting patterns of polymorphisms at the ABO-secretor gene (FUT2) and plasma alpha(1, 3)fucosyltransferase gene (FUT6) in human populations. Genetics 158: 747-756.

13. Idikio HA (1997) Sialyl-Lewis-X, Gleason grade and stage in non-metastatic human prostate cancer. Glycoconj J 14: 875-877.

14. Kvist E, Krogh J, Hjortberg P (1992) Prognostic variables in patients with prostate cancer: Influence of blood group $A B O$ $(\mathrm{H})$, the Rhesus system, age, differentiation, tumour stage and metastases. Int Urol Nephrol 24: 417-423.

15. Hakomori S (1999) Antigen structure and genetic basis of histo-blood groups A, B and O: Their changes associated with human cancer. Biochim Biophys Acta 1473: 247-266.

16. Chihara $Y$, Sugano K, Kobayashi A, Kanai $Y$, Yamamoto $H$, et al. (2005) Loss of blood group A antigen expression in bladder cancer caused by allelic loss and/or methylation of the ABO gene. Lab Invest 85: 895-907.

17. Gao S, Worm J, Guldberg P, Eiberg H, Krogdahl A, et al. (2004) Genetic and epigenetic alterations of the blood group $A B O$ gene in oral squamous cell carcinoma. Int $\mathrm{J}$ Cancer 109: 230-237.

18. Cao X, Wen ZS, Sun YJ, Li Y, Zhang L, et al. (2014) Prognostic value of $A B O$ blood group in patients with surgically resected colon cancer. Br J Cancer 111: 174-180. 